\title{
A Cross-sectional Study of Female HIV Patient Perspective of Dyadic Adjustment in HIV Sero-concordant and Sero-discordant couples
}

\author{
*Sodeinde K.J. ${ }^{1}$, Olu-Abiodun O. $^{2}$, Bamidele E.F. ${ }^{3}$, Abiodun O.A. ${ }^{1}$
}

\begin{abstract}
Background: Dyadic Adjustment is defined as the process with which couples form a steady relationship. This study assessed dyadic adjustment in HIV couples in Ogun State, Nigeria.

Methods: This cross sectional study was carried out among 458 women accessing HIV care in tertiary hospitals in Ogun State, Nigeria. Participants were evaluated using the Revised Dyadic Adjustment Scale and analyzed using the Stata/SE 15.1 statistical Package. Chi-square and t-tests were used to determine the correlates of dyadic adjustment (Distress/Non-distress) while logistic regression was used to determine the predictors of distress.
\end{abstract}

Results: Only $28.82 \%$ had relationship distress while the majority $(71.18 \%)$ had no distress. There was a statistically significant association between marital status and the level of distress. Those who were currently married were less likely to have distress than those who were single or previously married.

Conclusion: Those who were not married were more predisposed to distress. More support for these groups is therefore recommended.

Keywords: Couple, Distress, Dyadic adjustment, HIV, Sero-concordant, Sero-discordant

*Corresponding author

Sodeinde K.J.

ORCID-NO: http://orcid.org/0000-0003-4964-2701

Email: kolawolesodeinde024@gmail.com

${ }^{1}$ Department of Community Medicine, Babcock University, Ilishan, Nigeria.

${ }^{2}$ The School of Nursing, Ijebu-Ode, Nigeria.

${ }^{3}$ Department of Community Medicine, Babcock University Teaching Hospital, Ilishan-Remo, Nigeria. 


\title{
Une étude transversale du point de vue des patientes séropositives sur l'ajustement dyadique dans les couples séro-concordants et séro- discordants du VIH
}

\author{
*Sodeinde K.J. ${ }^{1}$, Olu-Abiodun O. ${ }^{2}$, Bamidele E.F. ${ }^{3}$, Abiodun O.A. ${ }^{1}$
}

\section{Résumé}

Contexte général de l'étude: L'ajustement dyadique est défini comme le processus avec lequel les couples forment une relation stable. Cette étude a évalué l'ajustement dyadique chez les couples séropositifs dans l'État d'Ogun, au Nigéria

Méthode de l'étude: Cette étude transversale a été menée auprès de 458 femmes accédant aux soins du VIH dans les hôpitaux tertiaires de l'État d'Ogun, au Nigéria. Les participants ont été évalués à l'aide de l'échelle d'ajustement dyadique révisée et analysés à l'aide du progiciel statistique Stata/SE 15.1. Des tests du chi carré et $t$ ont été utilisés pour déterminer les corrélats de l'ajustement dyadique (détresse/nondétresse) tandis que la régression logistique a été utilisée pour déterminer les prédicateurs de détresse.

Résultat de l'étude: Seulement $28,82 \%$ avaient une détresse relationnelle tandis que la majorité $(71,18 \%)$ n'avait aucune détresse. Il y avait une association statistiquement significative entre l'état matrimonial et le niveau de détresse. Ceux qui étaient actuellement mariés étaient moins susceptibles de souffrir de détresse que ceux qui étaient célibataires ou mariés auparavant.

Conclusion: Ceux qui n'étaient pas mariés étaient plus prédisposés à la détresse. Un soutien accru pour ces groupes est donc recommandé.

Mots-clés: Couple, détresse, ajustement dyadique, VIH, séro-concordant, séro-discordant

*Corresponding author

Sodeinde K.J.

ORCID-NO: http://orcid.org/0000-0003-4964-2701

Email: kolawolesodeinde024@gmail.com

${ }^{1}$ Department of Community Medicine, Babcock University, Ilishan, Nigeria.

${ }^{2}$ The School of Nursing, Ijebu-Ode, Nigeria.

${ }^{3}$ Department of Community Medicine, Babcock University Teaching Hospital, Ilishan-Remo, Nigeria.

Research Journal of Health Sciences subscribed to terms and conditions of Open Access publication. Articles are distributed under the terms of Creative Commons Licence (CC BY-NC-ND 4.0). (http://creativecommons.org/licences/by-nc-nd/4.0)

http://dx.doi.org/10.4314/rejhs.v9i2.3 


\section{INTRODUCTION}

Dyadic Adjustment is defined as the process with which couples form a steady relationship (1). It manifests through the significant changes that occur in the way one perceives oneself and one's partner (1). The adjusted relationship may also be seen as one in which the partners form a good bond to resolve collective challenges satisfactorily even at those times when they have divergent views about issues (2). Components of dyadic adjustment include couple's consensus, couple's satisfaction, couple's cohesion and expressing emotions (1).

It has been documented that marital adjustment by both spouses largely depends on the ability of the man to express himself (3). However both partners need to adopt tactics to sustain their relationship (4). Some of these tactics will include relating with the one's partner with optimism, transparency, having a common network of friends, helping each other in carrying out duties and reassuring one's partner of commitment to the relationship (5). Studies have shown the benefits of these relationship maintenance tactics. Such include ability of couples to engage in more behaviours that can further strengthen their relationship (5), ability to restore relationships (60 and be flexible in relating with one another (5).

A new trend in HIV patient care focuses on helping him/her to live a full and normal life (1) as against just medical treatment. There is, therefore, a need to address the various social, cultural and other factors that encourage the transmission of the virus as part of national and international strategies. This will not only help to effectively control the pandemic, but it will also improve the quality of life of those living with the virus remarkably (7). Moreover, there is generally an increased consciousness of living a safe and healthy life. This includes getting adequate and apt information about HIV/AIDS and forming a healthy relationship with an HIVinfected person (1).

Sexual behavior among HIV seropositive and discordant couples can be understood better when one considers the quality and changes which occur in social relationships (8). Communication is crucial in preventing HIV among sero-concordant and discordant couples. It has been conjectured that effective communication to reach an agreement and other factors such as having a high degree of contentment, interrelatedness and friendliness are signs of a constructive relationship. Such couples will exhibit safer sexual behaviors like using condoms more often and avoiding multiple sexual partners (9).

Communication as regards mutual agreement on condom use cannot be overemphasized because HIV is most commonly transmitted within marriage and is determined by factors like condom use and presence of STIs (10). Moreover, couples do not adopt approaches to reduce sexual risks consistently. They may be more concerned about sensual gratification rather than their physical health which includes preventing HIV. This is demonstrated by low condom use even in stable and dedicated relationships (11). Nevertheless, getting married in certain cultures may be associated with prohibitions as regards communicating about contraceptives, Sexually Transmitted Infections including HIV and strategies to reduce these infections (12). These restrictions may be because of gender inequities such as cultural rules about fidelity (13). Condom use is also adversely affected by intimate partner violence (14).

Sero-discordant couples particularly face unique challenges and dyadic adjustment is imperative between partners. For instance, there is a need to minimize the risk of transmitting HIV to the HIV negative partner and to the offsprings (15). It has also been shown that many people in sero-discordant relationships have the desire to bear children. (16). Fewer numbers of living children, young age, the conviction that the spouse wanted children and organizational influences like discussing with health care workers were linked to fertility intentions. This desire to give birth limits the alternatives to minimize the risk of transmitting HIV among couples who are sero-discordant (17). This study was to assess dyadic adjustment among seroconcordant and sero-discordant HIV in Ogun State, Southwest Nigeria as this is important for both of them to lead a healthy and productive life.

\section{MATERIALS AND METHODS Study Area and Study Design}

This descriptive cross-sectional study was conducted in Ogun State, Southwest Nigeria. The state is bounded in the north by Oyo and Osun States, in the east by Ondo State, in the south by Lagos State and in the west by the Republic of Benin. The projected population for the state in 2016 was 5,217,700 (18).

In Ogun state, there are 2 federal tertiary health facilities, one state tertiary hospital, 39 public secondary hospitals, 450 primary health facilities, one private tertiary hospital, and 904 private health facilities (19). The study was 
carried out in three tertiary health facilities, namely Federal Medical Centre, Abeokuta (FMCA), Olabisi Onabanjo University Teaching Hospital (OOUTH) and Babcock University Teaching Hospital (BUTH)

\section{Study Population, Inclusion and Exclusion Criteria}

Respondents were women who were at least 18 years old living with HIV and receiving treatment in the selected tertiary hospitals within the state. We included women who have received care for at least 6 months and excluded sick women from the study

\section{Sample Size Estimation and Sampling Method}

A minimum sample size of 357 was estimated using the Cochran formula (20): $n=$ $z^{2} p q / d^{2}$, where $n$ is the desired sample size, $z$ is the normal standard deviation set at 1.96 (for $95 \%$ confidence level), $P$ is the prevalence of the characteristic of the study, $q$ is $1.0-p$ and $d$ is the desired degree of accuracy taking as 0.05 . The prevalence $(p)$ was taken as $36.6 \%$ from a previous related study in Uganda (21). A 10\% non-response rate was projected and added to the sample, making the minimum sample size to be 446. The researchers interviewed a total of 458 respondents. Based on the estimated number of female HIV-positive patients enrolled at each facility, we calculated a proportionate sample of patients required in each facility. Then, we recruited patients consecutively till the number allocated to each hospital was attained.

\section{Data Collection Tool, Data Management and Analysis}

The researchers evaluated participants using the Revised Dyadic Adjustment Scale (RDAS), developed by Graham B. Spanier. The RDAS is made up of 14 items that can be evaluated by one or both partners. For some of the items the subject must indicate the approximate extent to which they agree or disagree with their partners while for the remaining items, the subject must indicate the frequency of occurrence between him/her and the partner. We scored the items from 0-5. The RDAS includes 3 subscales: (a) Dyadic consensus which includes values, decision making, and affection (b) Dyadic satisfaction which comprises of conflict and stability (c) Dyadic cohesion which comprises of discussion and activities. The sum of the sub-total scores for each sub-scale was found. Total obtainable scores were 30, 20 and 19 for consensus, satisfaction, and cohesion respectively. The cut - off point to discriminate between distress and no- distress for consensus, satisfaction, and cohesion were 22, 14 and 11 respectively. A total score of 48 in all the parameters discriminate between distress and non-distress. We analyzed our data with Stata/SE 15.1 statistical Package. We calculated frequencies and percentages for categorical variables. We computed means and standard deviation for numerical variables and used the student's t-test and chi-square to determine correlates of dyadic adjustment (Distress/Nondistress). We used the multinomial logistic regression analysis to determine the predictors of distress.

\section{Ethics Consideration}

We explained the processes and goal of the study to the participants. Participation was voluntary, and participants could withdraw from the study at will without any consequences. A written informed consent was obtained from all study participants. We obtained Institutional Review Board (IRB) approval for this study (OOUTH/HREC/206/2018AP).

\section{RESULTS}

Table 1 shows the socio-demographic characteristics of the respondents. The mean age of the respondents was $41.82 \pm 10.27$ and majority of them $(60.7 \%)$ were married. A little above onethird of the respondents had secondary education $(37.77 \%)$ as the highest academic qualification while less than one-fifth $(17.9 \%)$ had tertiary education. Most $(86.46 \%)$ were employed. Almost all (98.69\%) the respondents had been commenced on HAART and $(37.12 \%)$ had been on the drugs for at least 60 months (5 years). Only a few $(11.35 \%)$ of the respondents were seroconcordant with their partners, while most (77.29\%) did not know the HIV status of their partners.

Table 2 shows the revised dyadic adjustment scores. Average scores for decision making, values and affection were $8.05 \pm 2.42$, $8.16 \pm 2.35$ and $7.87 \pm 2.53$ respectively out of a total score of 10 for each parameter. Subtotal score for relationship consensus was $24.04 \pm 7.13$ out of a total score of 30 . Average scores for relationship stability and conflict were $8.45 \pm$ 2.82 and $7.48 \pm 2.72$ respectively out of a total score of 10 for each parameter. Subtotal score for relationship satisfaction was $15.96 \pm 5.40$ out of a total score of 20. Average scores for activities was $4.61 \pm 2.19$ out of a total of 9 while average scores for discussion was $5.63 \pm 3.00$ out of a 
total score of 10. Subtotal score for relationship cohesion was $10.17 \pm 5.21$ out of a total score of 19. The total revised adjustment scale score was $49.90 \pm 14.19$ out of a total score of 69 . Only a little above one-quarter $(28.82 \%)$ had relationship distress with a total score of less than 48 on the revised dyadic adjustment scale while the majority $(71.18 \%)$ had no distress in their relationships.

Table 3 shows participants' characteristics and bivariate relationships with the Dyadic scale. There was a statistically significant association between marital status and level of distress $(\mathrm{p} \leq 0.001)$. However, the associations between age, level of education and occupation were not significant with $\mathrm{P}$ values of $0.271,0.592$ and 0.948 respectively.

Table 4 shows factors associated with distress. Those who were currently married $(\mathrm{OR}=$ $0.381,95 \%$ C.I $=0.172-0.843, \mathrm{P}=0.017$ ) were less likely to have distress than the single.

\section{DISCUSSION}

The type of marital relationship where a partner is willing to discuss relationship challenges while the other partner is withdrawn and avoids such discussion is detrimental for a healthy affair (22). Such for instance may be seen in disclosure of HIV status to one's partner. Like many developing countries $(23,24)$, many HIV patients in Nigeria do not disclose their serostatus to their partners (25). This may be counterproductive to the global efforts in addressing the scourge of the HIV/AIDS pandemic as the uninfected partner may not take necessary precautions to prevent contracting the disease. Several factors have been implicated in the non-disclosure of an individual's positive sero-status to the partner in Nigeria. These include unmarried couples, polygamous marriage, anticipating inadequate backing from the partner, ignorance of partner's seropositivestatus, poor self- esteem, fear of possible divorce or intimate partner violence and inadequate support from the health care workers $(25,26)$. Sero-discordant Couples are commonly implicated in new HIV infections in Sub-Saharan Africa (27) with the risk of transmitting the disease to the uninfected partner nearly doubling with the pregnancy of the female partner (28). The association between sero-discordant couples and most new HIV infections in Sub-Saharan Africa may be because of the high level of nondisclosure among them.

In the same vein, this current study revealed that only a few $(11.35 \%)$ of the respondents was sero-concordant while another $11.35 \%$ were sero-discordant with their partnerss. The majority (77.29\%) did not know the HIV status of their partners. With the poor knowledge of partners' serostatus, there is a need to sustain the provision of HAART and encourage interventional programmes to prevent transmitting HIV from positive partner to unsuspecting negative partners while ensuring couples are helped to achieve their reproductive goals. These programmes may include the promotion of contraception use particularly condom which not only prevents transmission of the virus but also reduce the risk of unwanted pregnancies which may further predispose the other partner to the infection (28). Other key interventional programmes may include health education in the context of the importance of disclosure of positive HIV status to partner and health workers' support in ensuring the same. Uptake of HIV screening at interval may also be encouraged and the use of post exposure prophylaxis where and when appropriate.

The finding of low sero-concordant status in this current study was at variance with what was reported in a similar study in Romania where as much as $50 \%$ of the couples were seroconcordant (1). This may reflect higher serostatus disclosure to partner in the Romanian study as compared to this current study which is conducted in Nigeria, Sub Saharan Africa where disclosure of HIV status is poor (25) and stigmatization of HIV positive patients is high $(29,30)$.

On the other hand, the mean age of 41.82 years of respondents in this current study was almost twice the median age of 23 years of the Romanian study. So lower sero-concordant status observed in this current study may not only be due to poor disclosure by partners but also because participants were older and could have been more cautious in their sexual activities such as practicing safe sex with reduced risk of transmission to their partners. Moreover, most of the participants in this current study were married and this could have made them more responsible for their sexual lives, unlike unmarried individuals that may have had multiple partners and other risky behaviours, increasing their chances of infection.

Dyadic cohesion considers mutual discussions and activities. It is about couples' ability to deliberate on important issues together and be able to execute them. In this current study, there was a low score for cohesion, unlike consensus and satisfaction that had high scores. 
Low cohesion may affect mutual agreement among couples and prevent achieving a common reproductive goal. In contrast to this finding, a similar study in Europe reported high scores for consensus and cohesion (1). However, a study conducted in America showed varied level of cohesion among couples depending on their definition of certain relationship issues (31).

This current study identified a relationship between marital status and distress. Those who were currently married were less likely to be distressed in their relationship when compared to those who were never married or who were previously married. Similar to this finding, a study to assess the relationship between marital status and psychological distress among Latinos in the United States reported higher levels of psychological distress among the divorced, separated, single or those cohabiting as compared to those who were married (32). In the same vein, depressive symptoms have been documented to be more in the single and divorced compared to the married (33). The higher level of distress among the single might be a result of the lack of support that married people would have enjoyed from their spouses. A lower level of support and a higher level of cultural conflict have been linked to psychological distress (32). However, in contrast to this study, a study conducted in the USA reported that depressive symptoms were commoner among married individuals than among single, divorced or widowed (34). This disparity in the level of distress among the single and married in our study and the American study may be related to differences in socio-economic and cultural factors in the two climes.

The Revised Adjusted Scale was used to assess factors associated with distress in this study. However, a qualitative method of data collection could have elicited more detailed information from respondents about factors related to distress and forming a positive relationship with the partner.

\section{CONCLUSION}

The majority of individuals living with HIV/AIDS did not know the sero-status of their partners. The total revised adjustment scale score was $49.90 \pm 14.19$ out of a total score of 69 , A lesser proportion of HIV positive persons who were currently married were distressed compared to those who were single or previously married. With a higher level of distress among those who are not currently married, there is a need for more, well-orchestrated support for these groups at all health facilities.

Acknowledgments: The participants of this study are appreciated for their contributions to this research.

Conflict of interest: The authors of this paper have declared no conflict of interest.

Authors' contributions: OA conceived the research idea KS wrote the first draft. All authors reviewed the manuscript and approved the final submission

\section{REFERENCES}

1. Largu A, Manciuc C, Vata A, Nicolau C, Prisacaru L, Clubotaru F et al. Dyadic adjustment in HIV seroconcordant and serodiscordant couples. Rev Med Chir Soc Med Nat, lasi. 2012; 116(3): 71821

2. Locke HJ, Wallace EM. Short marital adjustment and prediction tests: Their reliability and validity. J Mar Fam Living. 1959; 21(3): 251-55

3. Leanne KL Marital adjustment among rural couples: The role of expressiveness .Sex Roles 1989;21:579-590

4. Ayres J. Strategies to maintain relationships: Their identification and perceived usage. Communication Quarterly.1983;31:62-67

5. Canary D, Stafford L and Semic BA. A panel study of the associations between maintenance strategies and relational characteristics. Journal of Marriage and Family. 2002; 64:395-406.

6. Guerrero LK, Eloy SV and Wabnik AI. Linking maintenance strategies to relationship development and disengagement: A reconceptualization. Journal of Social \& Personal Relationships. 1993; 10:273-283

7. Spanier GB. Manual for the Dyadic adjustment Scale. North Tonawanda, NY. A multi-health system; 1989.

8. Vamos S, Cook R, Chitalu N, Mumbi M, Weiss SM, Jones D. Quality of relationship and sexual risk behaviors among HIV couples in Lusaka, Zambia. AIDS Care. 2013;25(9): 1102- 8

9. Sales JM, Lang DL, Di-Clement RJ, Latham TP, Wingood GM, Hardin JW et al. The mediating role of partner communication frequency on condom use among African American adolescent females participating in an HIV prevention intervention. Health Psychole. 2012; 31(1):63-9.

10. Marfatia YS, Naik E, Singhai P, Naswa S. Profile of HIV seroconcordant/discordant couples a clinic-based study at Vadodara, India. Indian J Sex Transm Dis AIDs. 2013; 34(1): 5-9

11. Warren JT, Harvey SM, Agnew CR. One Love; Explicit monogamy agreements among heterosexual young adult couples at increased risk of sexually transmitted infections. J Sex Res. 2012; 49(2-3):282-9 
12. Marlow HM, Tolley EE, Kohl R, Mehendale S. Sexual communication among married couples in the context of a microbicide clinical trial and acceptability study in Pune, India. Cult Health Sex. 2010; 12(8): 899-912

13. Njau B, Watt MH, Ostermann J, Manongi R, Sikkema KJ. Perceived acceptability of homebased couples voluntary HIV counseling and testing in northern Tanzania. AIDS Care. 2012; 24(4): 413-9

14. Swan $\mathrm{H}$ and $\mathrm{O}^{\prime}$ Connell DJ. The Impact of Intimate Partners Violence on women's condom negotiation efficacy. J Interpers Violence. 2012; 27(4): 775-92

15. Gilling- Smith C, Nicopoullos JD, Semprini AE, Frodsham LC. HIV and reproductive care; a review of current practice. BJOG. 2006;113(8) :869-78

16. Martins A, Alves S, Chaves C. Prevalence and factors associated with fertility desires/intentions among individuals in HIV-serodiscordant relationships: a systematic review of empirical studies. J Int Aids So. 2019; 22: e25241

17. Mmeje O, Cohen CR, Murage A, Ong'ech J, Kiarie J, Van der Poel S. Promoting reproductive options for HIV affected couples in sub-Saharan Africa. BJOG. 2014; 121(5): 79-86

18. Ogun State Nigeria Population Statistics Charts, Map and Location. Available at . Accessed on 20/06/12

19. Ogun State. Health Facility Listing in Ogun State. A v a i 1 a b 1 e a t www.library.procurementmonitor.org.files. Accessed on 12/06/18

20. Cochran WG. Sampling Techniques. 2nd ed.. New York: John Wiley and Sons, Inc.; 1963

21. Osinde MO, Kaye DK, Kakaire O. Intimate partners' violence among women with HIV infection in rural Uganda: critical implications for policy and practice. BMC women's Health. 2011; 11(1): 50

22. Caravelli L, Lubrano-Lavadera A, Malagoli Togliatti M. T08-P-01 Communication patterns and dyadic adjustment of couples: a preliminary study. Sexologies 2008; 17(1):S112

23. Ramlagan S, Matseke G, Rodriguez VJ, Jones DL, Peltzer K, Ruiter RAC et al. Determinants of disclosure and non-disclosure of HIV-positive status, by pregnant women in rural South Africa. Sahara J 2018; 15(1): 155-163

24. Hallberg D, Kimarion TD, Mtuya C, Msuya M,
Bjorling G. Factors affecting HIV disclosure among partners in Morongo, Tanzania. Int J Afr Nurs Sc 2019; 10:49-54

25. Amoran OE. Predictors of disclosure of serostatus to sexual partners among people living with HIV/AIDS in Ogun State, Nigeria. Nigerian Journal of Clinical Practice. 2012; 15(4): 385-90

26. Odiachi A, Erekaha S, Cornelius LJ, Isah C, Ramadhani HO, Rapoport L et al. HIV status disclosure to male partners among rural Nigerian women along with the prevention of mother to child transmission of HIV cascade: a mixedmethods study. BMC Reprod Health. 2018; 15(1): 36

27. Dunkle KL, Stephenson R, Karita E, Chomba E, Kayitenkore K, Vwalika C et al. New Heterosexually Transmitted HIV Infections in Married or Cohabiting Couples in Urban Zambia and Rwanda: an analysis of Survey and Clinical Data. Lancet. 2008; 371(9631): 22183-91

28. Brubaker S, Bukusi E, Odoyo J, Achando J, Okumu A, Cohen CR. Pregnancy and HIV transmission among HIV discordant couples in a clinical trial in Kisumu, Kenya. HIV Med. 2011;12(5):316-21

29. Greeff M, Phetlhu R, Makoae LN. Disclosure of HIV Status: experiences and perceptions of persons living with HIV/AIDS and nurses involved in their care in Africa. Qual Health Res. 2008; 18(3): 311-24.

30. Ncama BP, Mclnerney PA, Bhengu BR. Social Support and medication adherence in HIV disease in Kwazulu-Natal, South Africa. Int J Nurs Stud. 2008; 45(12):1757-63

31. Fitzpatrick MA and Best P. Dyadic Adjustment in Relational Types: Consensus, Cohesion, Affectional Expression, and Satisfaction in Enduring Relationships. Communication Monographs. 1979; 46:167-178

32. Darghouth S, Brody L, Alegria M. Does Marriage Matter? Marital status, Family Processes, and Psychological Distress among Latino men and women. Hispanic J Behav Sci. 2015; 37(4):482502

33. Hope S, Rodgers B, Power C. Marital status transitions and psychological distress: longitudinal evidence from a national population sample. Psychol Med. 1999; 29(2): 381-9

34. Choi NG, Jung-Hwa Ha. Relationship between spouse/partner support and depressive symptoms in older adults: Gender difference. Aging Ment Health 2011; 15(3): 307-17

How to cite this article:

Sodeinde K.J., Abiodun O.A., Olu-Abiodun O., Bamidele E.F. A Cross-sectional Study of Female HIV Patient Perspective of Dyadic Adjustment in HIV Sero-concordant and Sero-discordant couples. Research Journal of Health Sciences, 2021,9(2): 133-141 
Table 1: Socio-demographic and HIV Characteristics of Respondents

\begin{tabular}{lll}
\hline Variable & Frequency & Percentage \\
\hline Age (Years) & & \\
$20-29$ & 40 & 8.73 \\
$30-39$ & 177 & 38.65 \\
$40-49$ & 141 & 30.79 \\
$50-59$ & 67 & 14.63 \\
$\geq 60$ & 33 & 7.20 \\
Marital Status & & \\
Single (Never Married) & 29 & 6.33 \\
Currently Married & 278 & 60.7 \\
Previously Married & 151 & 32.97 \\
Education & & \\
No formal education & 36 & 7.86 \\
Primary & 167 & 36.46 \\
Secondary & 173 & 37.77 \\
Tertiary & 82 & 17.90 \\
Occupation & & \\
Unemployed & 52 & 11.36 \\
Employed & 396 & 86.46 \\
Retired & 10 & 2.18 \\
HAART & & \\
Yes & 452 & 98.69 \\
No & 6 & 1.31 \\
Duration of HAART (MONTHS) & & \\
0-11 & 88 & 19.21 \\
12-59 & 200 & 43.67 \\
$\geq 60$ & 170 & 37.12 \\
Sero-concordance & & \\
Yes & 52 & 11.35 \\
No & 52 & 11.35 \\
Don't Know & 354 & 77.30 \\
\hline
\end{tabular}

Table 2: Revised Dyadic Adjustment Scale

\begin{tabular}{llll}
\hline Scale & Score & Frequency & Percentage \\
\hline 1.Consensus & & & \\
Decision Making & $8.05 \pm 2.42$ & & \\
Values & $8.16 \pm 2.35$ & & \\
Affection & $7.87 \pm 2.53$ & & \\
Subtotal & $24.04 \pm 7.13$ & & \\
2. Satisfaction & & & \\
Stability & $8.45 \pm 2.82$ & & \\
Conflict & $7.48 \pm 2.72$ & & \\
Subtotal & $15.96 \pm 5.40$ & & \\
3.Cohesion & & & \\
Activities & $4.61 \pm 2.19$ & & \\
Discussion & $5.63 \pm 3.00$ & & \\
Subtotal & $10.17 \pm 5.21$ & & \\
Total & $49.90 \pm 14.19$ & & \\
Relationship distress & & 132 & \\
$\quad$ Yes & & 326 & 71.18 \\
No & & & \\
\hline
\end{tabular}


Table 3: Participants' Characteristics and Bivariate Relationship with Dyadic Scale

\begin{tabular}{|c|c|c|}
\hline \multirow[t]{2}{*}{ Variable } & \multicolumn{2}{|l|}{ RDAS } \\
\hline & Non Distress & Distress \\
\hline Age & $41.48 \pm 10.39$ & $42.65 \pm 9.94$ \\
\hline $\mathrm{t}(\mathrm{P}$-value $)$ & $-1.102(0.271)$ & \\
\hline \multicolumn{3}{|l|}{ Education } \\
\hline No formal education & $23(63.89)$ & $13(36.11)$ \\
\hline Primary & $122(73.05)$ & $45(26.95)$ \\
\hline Secondary & $120(69.36)$ & $53(30.64)$ \\
\hline tertiary & $61(74.39)$ & $21(25.61)$ \\
\hline $\mathrm{X}^{2}(\mathrm{P}$-value $)$ & $1.909(0.592)$ & \\
\hline \multicolumn{3}{|l|}{ Occupation } \\
\hline Unemployed & $38(73.08)$ & $14(26.92)$ \\
\hline Employed & $281(70.96)$ & $115(29.04)$ \\
\hline retired & $7(70.00)$ & $3(30.00)$ \\
\hline $\mathrm{X}^{2}(\mathrm{P}$-value $)$ & $0.107(0.948)$ & \\
\hline \multicolumn{3}{|l|}{ Marital Status } \\
\hline Single, never married & $17(58.72)$ & $12(41.38)$ \\
\hline Currently married & $219(78.78)$ & $59(21.22)$ \\
\hline Previously married & $90(59.60)$ & $61(40.40)$ \\
\hline $\mathrm{X}^{2}(\mathrm{P}$ Value $)$ & $19.917(<0.001)$ & \\
\hline \multicolumn{3}{|l|}{ Sero-concordance } \\
\hline Concomitant & $39(75.00)$ & $13(25.00)$ \\
\hline Discordant & $41(78.85)$ & $11(21.15)$ \\
\hline $\mathrm{X}^{2}$ (P Value $)$ & $0.217(0.642)$ & \\
\hline \multicolumn{3}{|l|}{ HAART } \\
\hline No & $6(100.00)$ & $0(0.00)$ \\
\hline Yes & $320(70.80)$ & $132(29.20)$ \\
\hline $\mathrm{X}^{2}(\mathrm{P}$ value $)$ & $2.462(0.189)$ & \\
\hline Duration of HAART (months) & $50.95 \pm 44.66$ & $45.85 \pm 43.69$ \\
\hline $\mathrm{X}^{2}(\mathrm{P}$ Value $)$ & $1.116(0.265)$ & \\
\hline
\end{tabular}

Table 4: Factors Associated with Distress

\begin{tabular}{llll}
\hline Variable & Odds Ratio & $\mathbf{9 5 \%}$ C.I & P-Value \\
\hline Marital Status & & & \\
Single, never married & Reference & & \\
Currently Married & 0.381 & $0.172-0.843$ & 0.017 \\
Previously married & 0.960 & $0.428-2.153$ & 0.921 \\
\hline
\end{tabular}

Distress is outcome Variable 